\section{Commentary: Highly selected: Endovascular arch repair after surgery for type A dissection}

\author{
Leora B. Balsam, MD
}

The spectrum of treatment options for disease of the aortic arch continues to expand with new innovations in endovascular devices. While open total arch replacement has long been a gold standard for many acute and chronic arch pathologies, less-invasive approaches are finding a role in the treatment armamentarium. Several branched endovascular grafts have been designed to allow for proximal landing in zone 0 (the ascending aorta). These include 3 commercially produced devices: (1) the Nexus stent graft (Endospan, Herzliya, Israel), a 2-piece off-the-shelf device with a side branch for the innominate artery; (2) the RelayBranch stent graft (Terumo Aortic, Glasgow, United Kingdom), a custom-designed device with 2 inner tunnels for connection to supra-aortic extensions in the innominate and left common carotid arteries; and (3) the Cook branched arch endograft (Cook Medical, Bloomington, Ind), a custom device with 2 inner side branches for the innominate trunk and left common carotid artery. These devices have been used to treat chronic pathologies of the arch in patients deemed high risk for surgery in ongoing or previous small feasibility studies. ${ }^{1-5}$ In most cases, the underlying aortic pathology has been aneurysmal disease. A smaller subset of patients has been treated for aneurysmal dilation of chronic aortic arch dissections, most often after previous proximal repair of acute type A dissection.

In this issue of the Journal, D'Onofrio and colleagues ${ }^{6}$ describe their experience at the University of Padova with

\footnotetext{
From the Division of Cardiac Surgery, UMass Memorial Medical Center, Worcester, Mass.

Disclosures: The author reported no conflicts of interest.

The Journal policy requires editors and reviewers to disclose conflicts of interest and to decline handling or reviewing manuscripts for which they may have a conflict of interest. The editors and reviewers of this article have no conflicts of interest.

Received for publication May 18, 2020; revisions received May 18, 2020; accepted for publication May 21, 2020; available ahead of print June 1, 2020.

Address for reprints: Leora B. Balsam, MD, Division of Cardiac Surgery, UMass Memorial Medical Center, University Campus, 55 Lake Ave North, Worcester, MA 01655 (E-mail: leora.balsam@umassmemorial.org).

JTCVS Techniques 2020;3:9-10

2666-2507

Copyright (C) 2020 The Authors. Published by Elsevier Inc. on behalf of The American Association for Thoracic Surgery. This is an open access article under the CC BY-NCND license (http://creativecommons.org/licenses/by-nc-nd/4.0/).

https://doi.org/10.1016/j.xjtc.2020.05.023
}

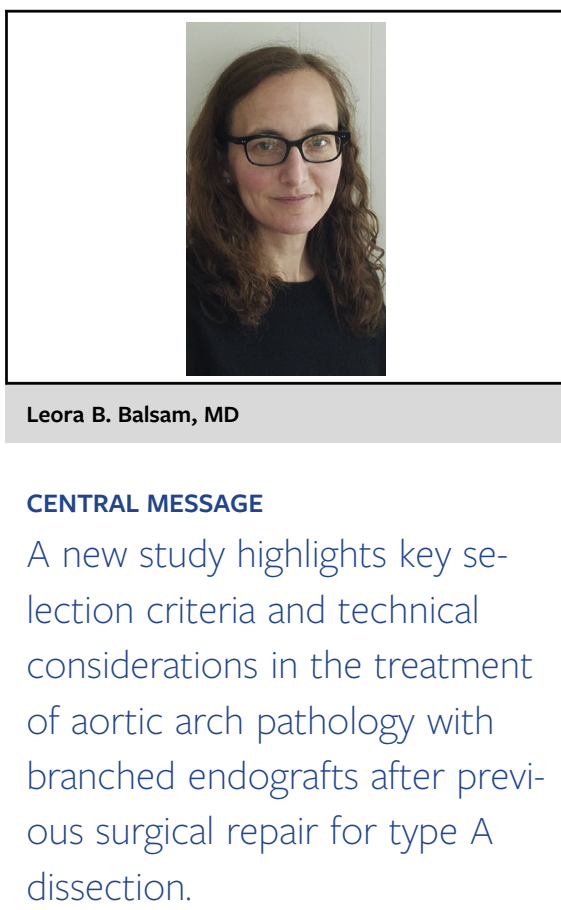

branched endovascular stent graft repair for arch disease in 4 patients who previously underwent repair of type A dissections with bio-Bentall procedures. Both the Nexus and RelayBranch devices were used for treatment of aneurysmal arch dissection (3 patients) and distal anastomotic pseudoaneurysm (1 patient). The authors describe 100\% technical success, no major adverse events, no endoleaks, and $100 \%$ survival at mean follow-up of 28 months. These initial results are very encouraging, but are we ready to replace our gold standard open repair with this new technique?

It is important to understand that patient selection for treatment with these devices is quite nuanced. Specifically, there are anatomic criteria that must be met. These include an adequate length and curvature in the proximal landing zone. Often this is not available in patients with previous proximal open aortic repair due to (1) short graft length between the sinotubular junction and the innominate trunk or (2) kinking of the interposition graft due to excess length. For patients without previous proximal aortic surgery, the presence of proximal aortic dilatation often precludes safe landing in zone 0 , as the risk of retrograde dissection is increased in the presence of proximal aortic disease. The standard delivery system for these devices traverses the aortic valve, so a preexisting mechanical aortic valve is also a contraindication to its use. A modified tip-free delivery system has 
been described in a single case with the Cook branched arch endograft. ${ }^{7}$

Other anatomic characteristics that are unfavorable for endovascular repair are significant atheroma, thrombus, or calcification in the aortic arch and target branch vessels due to risk of embolism, aneurysmal disease of the supraaortic vessels that prevents a good seal on the side branches, and underlying connective tissue disorder. In the limited series that have been reported, investigators have generally described significant learning curves, with better outcomes in the later experience for both the Cook and RelayBranch devices. ${ }^{2,5}$ There is significant planning for these procedures, including customization for the Cook and RelayBranch devices, which currently limits the applicability to chronic pathologies in nonemergency settings. Open surgery still remains more versatile, but for select patients, including those described in the report by D'Onofrio and colleagues, branched endografts have a burgeoning role.

\section{References}

1. D'Onofrio A, Antonello M, Lachat M, Planer D, Manfrin A, Bagno A, et al. Endovascular treatment of aortic arch aneurysm with a single-branched double-stage stent graft. J Thorac Cardiovasc Surg. 2017;154:e75-7.

2. Ferrer C, Cao P, Coscarella C, Ferri M, Lovato L, Camparini S, et al. Italian registry of double inner branch stent graft for arch pathology. J Vasc Surg. 2019;70: 672-82.

3. Czerny M, Rylski B, Morlock J, Schrofel H, Beyersdorf F, Saint Lebes B, et al. Orthotopic branched endovascular aortic arch repair in patients who cannot undergo classical surgery. Eur J Cardiothorac Surg. 2018;53:1007-12.

4. Spear R, Haulon S, Ohki T, Tsilimparis N, Kanaoka Y, Milne CPE, et al. Editor's choice-subsequent results for arch aneurysm repair with inner branched endografts. Eur J Endovasc Surg. 2016;51:380-5.

5. Haulon S, Greenberg RK, Spear R, Eagleton M, Abraham C, Lioupis C, et al. Global experience with an inner branched arch endograft. J Thorac Cardiovasc Surg. 2014;148:1709-16.

6. D’Onofrio A, Cibin G, Antonello M, Battocchio P, Piazza M, Caraffa R, et al. Endovascular exclusion of the entire aortic arch with branched stent-grafts after surgery for acute type A dissection. J Thorac Cardiovasc Surg Tech. 2020; 3:1-8.

7. Spear R, Azzaoui R, Maurel B, Sobocinski J, Roeder B, Haulon S. Total endovascular treatment of an aortic arch aneurysm in a patient with a mechanical aortic valve. Eur J Vasc Endovasc Surg. 2014;48:144-6. 